\title{
Simulation the Diagnosis of Beds Capacity Management in Departments of Urology and Thoracic and Vascular in Hospitals
}

\author{
Zinah Salih Hussein \\ Lecturer, Computer science, Al Mustansiriyah \\ University, Baghdad_Iraq
}

\author{
Basim Khudair Abbas \\ Lecturer, Mathematic science Al Mustansiriyah \\ University, Baghdad_Iraq
}

\begin{abstract}
The proposed system used to simulation health service by introduce the best medical care for the patient without any delay. the good treated is more effective to find balance between the health services in the hospital and indicators adopted by evaluated actual bed capacity of hospital. The aims in this paper decrease the number of patients (high bed stead's occupy) in some department, and vice verse in the rest departments, and distribute the bed stead's in the departments (Urology and Thoracic and Vascular) equally. As this study concluded a some recommendations by increase the number of doctors in order to suit the number of patients to reduce wait time.
\end{abstract}

\section{Keywords}

Department, Urology, Thoracic and Vascular, Patient, Hospital, Time of Stay (ToS), Bed Occupancy, Bed, Nurses, Physicians, beds capacity, Operation Room (OR), month.

\section{INTRODUCTION}

The Simulation used to learn the learners and educators by play an important role in medical and nursing education. also used in physical assessment skills and communication techniques taught by using student pairs. Furthermore trained simulated patients helped to simulate a psychiatric interactions, as well as the specialists try to understand how effect simulation on life of patients. teachers provided a dual role for allowing students to describes prostate models in live of female pelvic and male to improve their exam techniques used in the model, and comparing with real time to describe the pelvic or prostate exam.[1].

The urinary system consists of the kidneys, ureters, bladder, and urethra. The key elements in the system are the kidneys, a pair of purplish-brown organs located below the ribs toward the middle of the back the job of kidneys are remove excess liquid and wastes from the blood in the form of urine, keep a stable balance of salts and other substances in the blood, and produce a hormone that aids the formation of red blood cells. also ureters is a sack-like organ in the lower abdomen help to carry urine from the kidneys to the bladder, finally urine is stored in the bladder and emptied through the urethra, therefore urinary system represent an important part in body of human and is prone to injury of serious health problem such as Urinary Tract Infections (UTIs) which represent a second most common type of infection in the body. Women are especially prone to UTIs more than man but can be very serious when they do occur.[3]

Thoracic trauma causes from the adverse effects of indoor air pollution on health and comfort and maybe leading to death people and some cases requires to emergency thoracic as part of their initial resuscitation such as ( thoracic hemorrhage, airembolism, cardiac massage and cross-clamping of the descending aorta). Therefore to control states of thoracic trauma required to improve indoor air quality (e.g. air cleaners, vacuum cleaners, radon measurement and mitigation) and prevent concentrations of pollutants. [2]

\subsection{Beds Capacity Management in Hospitals}

Movement of patients from the emergency areas to inpatient beds is the responsibility of the Bed Control Unit (BCU). This is coordinated with the staff in the emergency room as well as the hospital wards. Moreover, the Nursing Department has assigned individuals to monitor bed availability; physicians are also consulted on the appropriateness of each movement. Therefore, the bed management process involves several jurisdictions and individuals. The bed control unit locates beds for ED patients based on diagnosis, and contacts the appropriate people in the ED and the wards as soon as a bed is made available. Information on bed availability and forthcoming discharges comes from the information system and informal communications among staff. The BCU staff has difficulty getting an overall picture of bed availability because they are not always told as soon as a bed is freed up, and because delays in housekeeping can hold up bed assignments.[4]

\section{STUDY OBJECTIVES}

The objectives in this paper describes by a following steps :

1. Diagnose the defect sites to management the beds in medical departments and try to find a ways to improve the health situation.

2. Provide style helps to determined the energy clinical in Urology and Thoracic and Vascular.

\section{RELATED WORKS}

Atallah Ahmed Shaaban at 2011 discussed the concept of basic urology, physical examination and urologic symptoms such as Pain within the genitourinary tract usually arises from obstruction or inflammation. Referred pain was common. Inflammation of parenchyma produces severe pain and fever e.g. acute pyelone phritis, prostitutes and epididymo orchitis. Tumors usually not cause pain unless they produce obstruction or extend to adjacent nerves. [5]

Joseph Loscalzo at 2010 discussed the concept of Pulmonary diseases were major contributors to morbidity and mortality in the general population. Although advances in the diagnosis and treatment of many common pulmonary disorders had 
improved the lives of patients, these complex illnesses continue to affect a large segment of the global population. The impact of cigarette smoking cannot be underestimated in this regard, especially given the growing prevalence of tobacco used in the developing world. [6]

Yichun Zhao at 2012 presented a functional model of lung mechanics including a non-linear alveolar pressure volume curve and representation of the work of respiratory muscles during breathing. The model used to simulate the response to forced inspiration and expiration, and these simulations used to compared the standard results of lung function tests routinely performed in departments of lung medicine. The model simulated the characteristics of inspiratory and expiratory flow profiles seen in normal subjects, and in patients with obstructive or restrictive diseases.[7]

\section{SYSTEM DESCRIPTION}

The government hospital has a very important departments are thoracic and urology and operate a round the clock and receive an unspecified number of patients per day depending on the cases. Also the departments have two 12-hour shifts for physicians starting at 05:00 and 17:00 and three shifts for nurses starting at 05:00, 12:00, and 17:00. To find the suitability of clinical performance with the absorptive capacity of departments to receive patients and their compatibility with a number of physicians and nurses. The thoracic department has 50 bed capacity has 32 nurses, 6 physicians. In the Department of urology has, the number of physicians 9 and 26 is a number of nurses and 28 is a number of beds .

\subsection{Acknowledging with the Proposing System}

The proposed system is simulate the actual bed occupancy in departments of thoracic and urology model. A regular patient enters to hospital and remains in waiting room after picks a number, this number called the patient is assessed from a triage nurse by screens to specific type of disease and then patient toward to examination room to take treatment. In this case, check the number of beds is sufficient then the patients transfer to special room for purpose take the necessary care; otherwise discharge from hospital. On the other hand, If the patient's condition deteriorated such as bleeding in the blood vessels or get one break in the ribs, It is possible for internal bleeding in one of the kidneys or any one of the dangerous situations that requires transfer the patient to the Operating Room (OR) immediately to take necessary care. also after stabilizing the patient's condition and the number of beds is available then transferred to other lobby; otherwise patient leaves from hospital. as figure (1) summarize the patient flow through the hospital by a flow chart.

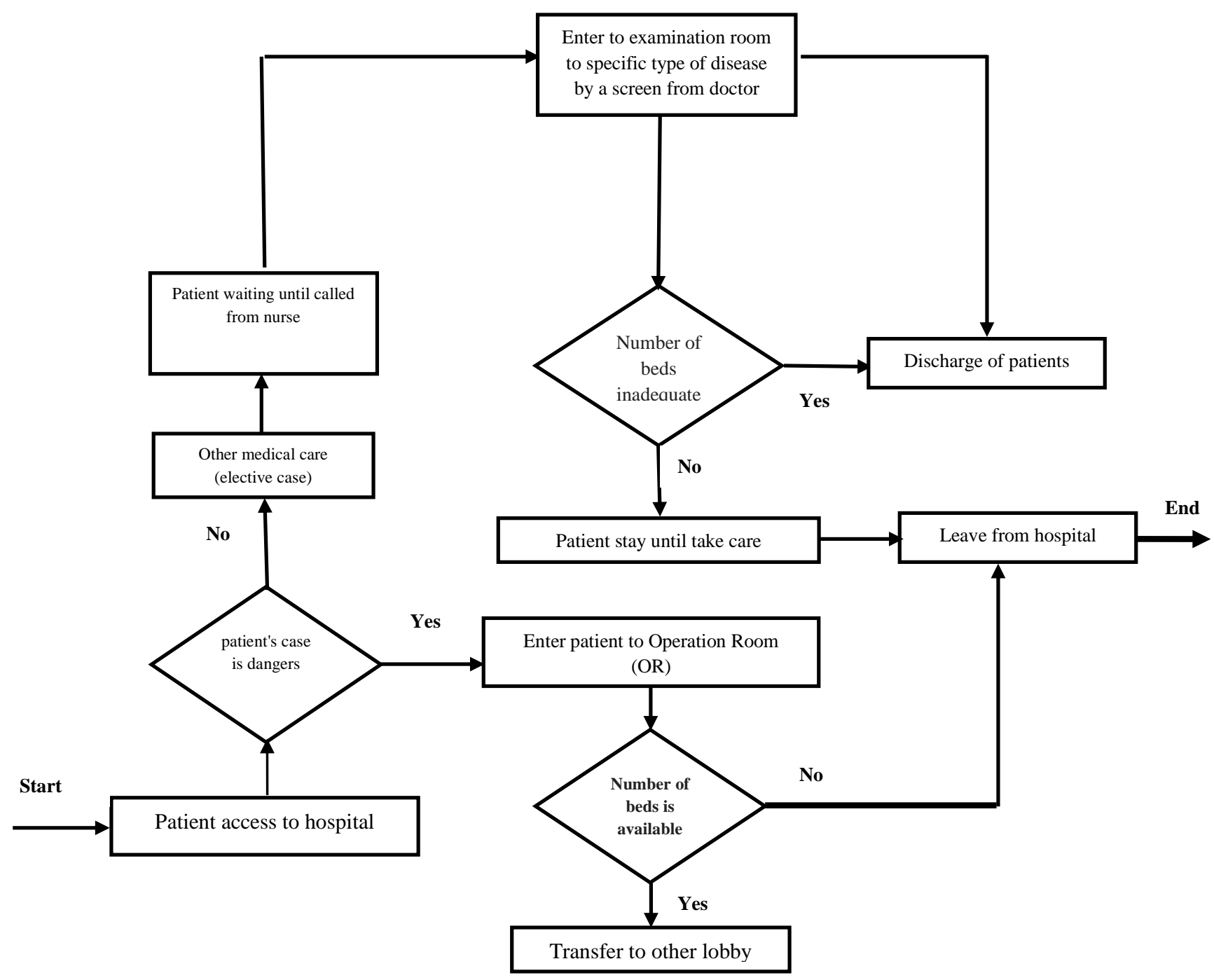

Figure (1) flow chart the patients flow in hospital 


\subsection{Evaluating Bed Capacity Options}

The occupancy rate at the hospital clinical depend on Time of Stay ((total sick days (day service) during the specified period of time ( month), whether an emergency or elective surgical, also depend on the number of beds, and number of days in this period.

Bed occupancy $=(($ Time of Stay $(\mathrm{ToS}) *$ number of patients leaving from hospital of specific month ) / (number of days in this period (month) * number of bed) $100 \%$

As well as the (ToS) rate of the patient in the hospital depends on the total days patients stay per month and the number of patients leaving from hospital of specific month.

Time of Stay $(\mathrm{ToS})=(($ Total days patients stay during the month) / ( number of patients leaving from hospital of specific month)).

\section{RESULTS AND DISCUSSION}

The simulation model created to classified two scenarios, each scenario have number of patients the incoming flow in each month, Total day of patients stay, Number of patients leaving from hospital, average of time stay, Number of Beds in each department. Whether the patients is Elective or Emergency conditions is simulated the operation of the system " Department of Urology and Department of Thoracic and Vascular in Iraq Hospitals ".

Scenario 1 - simulation of the "Urology Model" Operates Division is important part and caution in the hospital and the number of beds actual and predisposing to presence of occupancy rates high, especially for occupancy by patients (72) beds, Figure (2) shows a sample of the program tabular results to simulation model the highest number of patients breakers is 469 patients in the month of April corresponding to $\mathbf{7 6 \%}$ occupancy rate my bed. And the lowest number of patients in the month of August 241 patients offset by distracting my bed $\mathbf{5 2 \%}$ illustrated here the influence of the preparation of the patients on the high and low occupancy rate reached the highest for the establishment of $\mathbf{6 . 7}$ in the month of March, the number of patients, $\mathbf{3 1 3}$ patients , and lowest for the establishment of $\mathbf{3}$ in the month of September the number of patients, $\mathbf{4 4 8}$ patients. The highest occupancy rate in the month of March $93 \%$, and in spite of the small number of patients in this month, but there occupancy rate clinical high due to the length of patient survival, a 6.7 and a low occupancy rate was in the month of August stood at $\mathbf{5 2} \%$ and the reason for this is to the small number of patients in this month. The clinical occupancy rate during the months of the

\begin{tabular}{|l|l|l|l|l|l|l|}
\hline $\begin{array}{l}\text { Name } \\
\text { of } \\
\text { Month }\end{array}$ & $\begin{array}{l}\text { No. Day } \\
\text { Treatm } \\
\text { ent } \\
\text { Monthl } \\
\text { y }\end{array}$ & $\begin{array}{l}\text { Total } \\
\text { Day } \\
\text { Patient } \\
\text { Stay }\end{array}$ & $\begin{array}{l}\text { No. } \\
\text { patients } \\
\text { Breakers }\end{array}$ & $\begin{array}{l}\text { Averag } \\
\text { e Time } \\
\text { of Stay }\end{array}$ & $\begin{array}{l}\text { No. } \\
\text { Beds }\end{array}$ & $\begin{array}{l}\text { Bed } \\
\text { Occupanc } \\
\text { y }\end{array}$ \\
\hline $\mathbf{1}$ & 31 & 2027 & 397 & 5.1 & 72 & 90.71 \\
\hline $\mathbf{2}$ & 28 & 1206 & 320 & 3.8 & 72 & 60.32 \\
\hline $\mathbf{3}$ & 31 & 2107 & 313 & 6.7 & 72 & 93.96 \\
\hline $\mathbf{4}$ & 30 & 1657 & 469 & 3.5 & 72 & 76 \\
\hline $\mathbf{5}$ & 31 & 1986 & 453 & 4.4 & 72 & 89.3 \\
\hline $\mathbf{6}$ & 30 & 1685 & 453 & 3.7 & 72 & 77.6 \\
\hline $\mathbf{7}$ & 31 & 1630 & 455 & 3.6 & 72 & 73.39 \\
\hline $\mathbf{8}$ & 31 & 1170 & 241 & 4.9 & 72 & 52.91 \\
\hline $\mathbf{9}$ & 30 & 1333 & 448 & 3 & 72 & 62.22 \\
\hline $\mathbf{1 0}$ & 31 & 1427 & 375 & 3.8 & 72 & 63.84 \\
\hline $\mathbf{1 1}$ & 30 & 1666 & 405 & 4.1 & 72 & 76.88 \\
\hline $\mathbf{1 2}$ & 31 & 1449 & 484 & 3 & 72 & 65.05 \\
\hline
\end{tabular}

Figure(2) Tabular results of Beds occupancy and time of stay in department of urology year in this department can be observed in Figure(3).

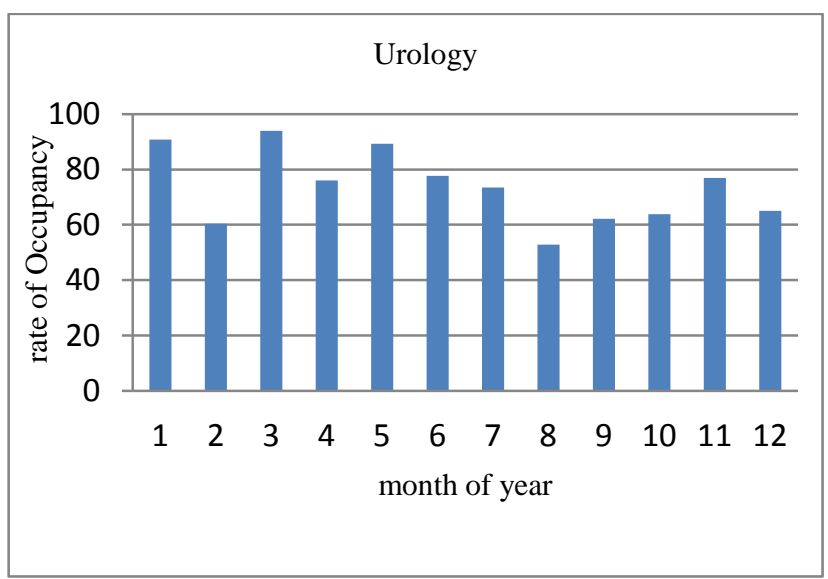

Figure(3) Occupancy rate in the Clinical Urology for all months in 2010

Scenario 2 - simulation of the "Thoracic and Vascular Model" This Division operates number of the beds (84), Figure (4) shows a sample of the program tabular results to simulation model below the highest number of patients in the month of July is 379 patients matched by a $\mathbf{6 8 \%}$ occupancy in my bed this month and the lowest number of patients in the month of October 232 patients matched by a $\mathbf{5 1 \%}$ occupancy bed. As for the length of stay, the stay of the highest in the month of May 6.1 and the lowest duration of residence in the month of September 2.5. The highest occupancy rate in the month of clinical May $\mathbf{7 5} \%$, and the lowest occupancy rate in the month of September $32 \%$. In other words, the high occupancy rate in the month of May clinical is due to the high number of patients and the time of stay, and lower occupancy rate in the month of September is due to the lack of stay of patients. occupancy rate of the division of clinical Thoracic surgery and vascular shows in Figure (5).

\begin{tabular}{|c|c|c|c|c|c|c|}
\hline $\begin{array}{c}\text { Nam } \\
\text { of } \\
\text { Mon } \\
\text { th }\end{array}$ & $\begin{array}{c}\text { No. } \\
\text { Day } \\
\text { Treatm } \\
\text { ent } \\
\text { Monthl } \\
\mathbf{y}\end{array}$ & $\begin{array}{c}\text { Tota } \\
\text { l } \\
\text { Day } \\
\text { Patie } \\
\text { nt } \\
\text { Stay }\end{array}$ & $\begin{array}{c}\text { No. } \\
\text { patien } \\
\text { ts } \\
\text { Break } \\
\text { ers }\end{array}$ & $\begin{array}{c}\text { Aver } \\
\text { age } \\
\text { Time } \\
\text { of } \\
\text { Stay }\end{array}$ & $\begin{array}{c}\text { N } \\
\text { O. } \\
\text { Be } \\
\text { ds }\end{array}$ & $\begin{array}{c}\text { Bed } \\
\text { Occupa } \\
\text { ncy }\end{array}$ \\
\hline $\mathbf{1}$ & 31 & 996 & 266 & 3.7 & 84 & \\
\hline $\mathbf{2}$ & 28 & 1302 & 281 & 4.6 & 84 & 54.96 \\
\hline $\mathbf{3}$ & 31 & 1357 & 291 & 4.7 & 84 & 52.52 \\
\hline $\mathbf{4}$ & 30 & 1139 & 324 & 3.5 & 84 & 45 \\
\hline $\mathbf{5}$ & 31 & 1957 & 323 & 6.1 & 84 & 75.66 \\
\hline $\mathbf{6}$ & 30 & 1746 & 361 & 4.8 & 84 & 68.76 \\
\hline $\mathbf{7}$ & 31 & 1795 & 379 & 4.7 & 84 & 68.41 \\
\hline $\mathbf{8}$ & 31 & 1599 & 269 & 5.9 & 84 & 60.95 \\
\hline $\mathbf{9}$ & 30 & 814 & 325 & 2.5 & 84 & 32.24 \\
\hline $\mathbf{1 0}$ & 31 & 1339 & 232 & 5.8 & 84 & 51.67 \\
\hline $\mathbf{1 1}$ & 30 & 1428 & 243 & 5.9 & 84 & 56.89 \\
\hline $\mathbf{1 2}$ & 31 & 1228 & 305 & 4 & 84 & 46.65 \\
\hline
\end{tabular}

Figure(4) Tabular results of Beds occupancy and time of stay in department of thoracic and vascular 


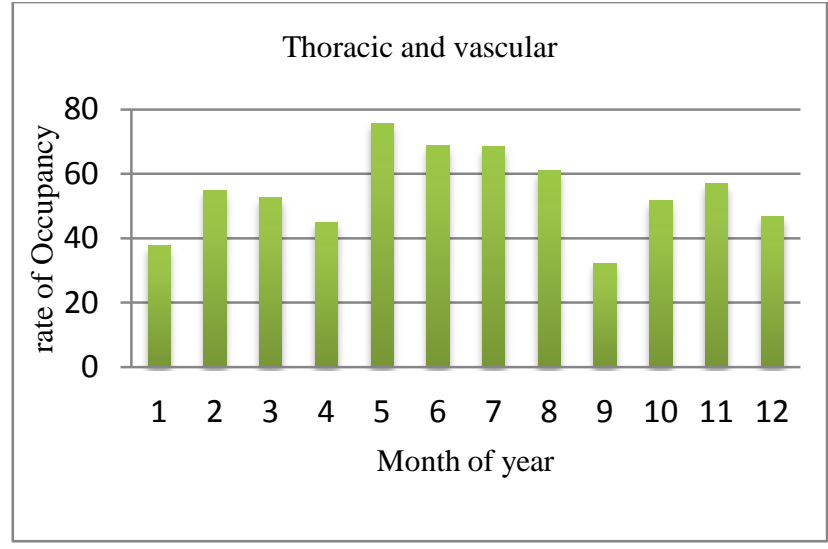

Figure(5) Occupancy rate of Clinical thoracic and vascular for all months in $\mathbf{2 0 1 0}$

\section{CONCLUSIONS}

The simulation model includes several features illustrative patients flow in hospital by a following steps :

- The clinical high occupancy in certain departments of surgery Urinary could up to $76-90 \%$ at certain times, compared to low bed occupancy in department of Thoracic and blood Vessels.

- The department of Urology has a highest number of patients. in the month of April have highest bed occupancy rate, in the month of August observed a lowest number of patients and the bed of occupancy is low, therefore can deduced how to effect the numbers of patients at high and low of occupancy rate. As well as the case for the Department of Thoracic has a high occupancy rate of clinical in the month of May because the number of patients and Time of Stay (ToS) are higher. The month of September observed a low occupancy rates because not stay any patients in this period.

- The number of doctors inadequate in both departments compared with the number of patients increasing, but contrary with the numbers of nurses is more needed .

\section{RECOMMENDATIONS}

There are a several recommendations for the development work in the hospital by a following steps :

- Reconsider the distribution of beds in departments of hospital, and how access to good planning and management for energy of beds depending on the size of demand for health services.

- Increase the number of doctors in order to suit with the number of patients in order to reduce wait time, and at the same time reduce the number of nurses and distributed as needed between departments.

\section{REFERENCES}

[1] Carol Fowler Durham, , Kathryn R. Alden "Enhancing Patient Safety in Nursing Education Through Patient Simulation", 2007.

[2] Kathryn R. Alden, "Emergency Thoracotomy in Thoracic Trauma a review", James Cook University Hospital, Marton Road, Middles brough, Cleveland TS4 3BW, UK, 2006

[3] National institutes of health, "Urinary Tract Infection in Adults", National Center for Health Statistics, Centers for Disease Control and Prevention, 2004.

[4] Randolph Hall, David Belson, "Modeling Patient Flows Through The Healthcare System", University of Southern California, Los Angeles, California 900890193, 2010

[5] Atallah Ahmed Shaaban, "Basic Urology", Urology and Nephrology Center Mansoura- Egypt, E-mail: shaaban1953@yahoo.com , 2011.

[6] Joseph Loscalzo, MD, PhD, "Pulmonary and CriticalCare Medicine", Harvard Medical School; Chairman, Department of Medicine; Physician-in-Chief, Brigham and Women's Hospital, Boston, 2012.

[7] Yichun Zhao, Stephen E Rees, Steen Andreassen, "Simulation of Pulmonary Pathophysiology During Spontaneous Breathing", Center for Model-based Medical Decision Support, Aalborg University, 2005. 